Acta Poetica 28 (1-2)

PRIMAVERA-OTOÑO

2007

\title{
La crisis del pensamiento
}

\author{
Norma Garza Saldívar
}

A partir de lo que Bajtín calificaba como la crisis del acto ético, es decir, como el abismo que separa la vivencia cotidiana e histórica del ser humano de sus formas de conocimiento, surge este ensayo como reflexión sobre el pensamiento alejado de la experiencia, del mundo de la cultura y de la vida. Por ello, conceptos como experiencia, realidad y lenguaje serán la base para acercarse desde diversas perspectivas a esa crisis del pensamiento.

This essay has its origin in what Bajtin called the crisis of the ethical act, that is, the abyss that separates daily and historical life experiences from the human beings from their forms of knowledge. It is a reflection on thought separated from experience, from the world of culture and life. Therefore, concepts such as experience, reality and language will be the basis for an exploration of this crisis of thought from diverse perspectives. 

Acta Poetica $28(1-2)$

PRIMAVERA-OTOÑO

2007

Norma Garza Saldívar

Universidad Autónoma de la Ciudad de México

\section{La crisis del pensamiento}

Sólo es fértil la búsqueda que excava, se sumerge, que es contracción del espíritu, descenso.

SAmuel Beckett

"Cuando creíamos haber llegado a puerto nos encontramos de nuevo en alta mar", escribe el filósofo alemán Leibniz refiriéndose al pensamiento; quizá porque el acto de pensar no deja de añadir nuevas dimensiones a la realidad y así jamás llegamos a un puerto, jamás nos detenemos, ya que al pensar se ejercen acciones sobre otras acciones, como un acto inagotable e inconcluso. Para retomar otra imagen del mar, qué mejor que traer a un escritor como Herman Melville, autor de Moby Dick, quien escribió alguna vez "me gustan los que se sumergen, cualquier pez puede nadar cerca de la superficie, pero sólo las grandes ballenas son capaces de descender más de cinco millas [...]. Desde que el mundo es mundo los buceadores del pensamiento regresan a la superficie con los ojos inyectados en sangre". Y es que pensar parece estar más ligado a la aventura, a la pérdida y al riesgo; por ello, el pensamiento bien 
puede remitirse al desamparo, al arrancarse de lo que ampara, de lo que protege, a salirse de aquella caverna de las sombras de la que hablaba Platón, en su diálogo de "La república o de lo justo". La analogía de Melville nos hace descender a lo más subterráneo y oscuro, nada más alejado del mundo tan iluminado en el que vivimos, el mundo que confunde la acción del pensamiento con la inercia de recoger lo ya establecido o de conformarse con las "verdades" que de tan transparentes se esfuman; verdades que niegan siempre el otro lado y muestran sólo una perspectiva. La realidad no es únicamente lo visible, la superficie de las cosas, de ahí que el pensamiento apele también al lado más oscuro y soterrado, a aquél que el poder dominante intenta siempre excluir y ocultar, negar y olvidar.

Para Foucault, el pensamiento no es una cuestión teórica sino un problema vital; como dice otro pensador francés, Gilles Deleuze, pensar "es afrontar la línea en la que necesariamente se juegan la muerte y la vida, la razón y la locura, una línea en la que uno se halla implicado" (1996: 145). Una línea que fascina por su oscilación, por la zozobra perpetua entre lo próximo y lo lejano. El pensamiento como la memoria se forjan sobre la experiencia, y parte de esa experiencia es la recepción, la receptividad del mundo; la experiencia del pensamiento es así apertura, no puede permanecer encerrado, de hecho, para Platón el pensamiento es diálogo. Por ello, pensar no es leer letras y atarse a los significados de lo dicho, sino provocar un discurso interior en el que se plasme la continuidad de la conciencia como memoria y pensamiento; es, en todo caso, una lectura como exégesis e interpretación. Pensar es así una experiencia, un acontecimiento. Si Melville dice que el buceador del pensamiento regresa con los ojos inyectados en sangre, quiere decir que pensar es un acto, que el sujeto pensante es afectado por la exterioridad; el pensador al que Melville se refiere, aquel que se parece a las ballenas, es afectado por la oscuridad, la presión y el silencio al penetrar hacia lo más pro- 
fundo; y cuando hablamos de profundidad podríamos también recordar aquella imagen de Paul Valéry de que "lo más profundo es la piel".

Así, pensar es una acción que afecta, pero que también ejerce una afección en el otro, en lo Otro. Porque cuando pensamos, los signos se fracturan, hay un quebrantamiento de la unidad de lo dado, pues se introducen diversas perspectivas que llevan a reconstruir las cosas desde otro sitio. Para pensar es necesario ser afectados por lo que nos rodea y quebrantarlo; es la exterioridad la que nos fuerza a pensar, a expresar mundos posibles e introducirlos nuevamente en la experiencia. Pensar no es saber ni ignorar sino buscar, y no se busca sino cuando nos dejamos afectar por algo o alguien, por un otro que arrastra al pensamiento a una búsqueda perpetua.

Quizá ahí radica el problema al que quiero llegar: hasta dónde nos hemos quedado con el pensamiento como una facultad y no como un acto emocional y volitivo; es decir como un acto ético, como lo entiende Mijaíl Bajtín. Filósofo ruso, que a principios de los años veinte calificaba la crisis del acto ético como la crisis de la palabra, es decir, como la cancelación de la responsabilidad, consideraba que "se ha creado un abismo entre el motivo del acto ético y su producto" (Bajtín, 1997:8); esto es, una separación entre la vivencia cotidiana e histórica del hombre y su proceso cognitivo, sus formas de conocimiento. En efecto, la idea de crisis remite no sólo a una idea de quebrantamiento sino también al abismo al que se refiere Bajtín, a la separación entre una cosa y la otra; y, por otro lado, crisis como momento crítico y decisivo que permite una transformación, un cambio, una metamorfosis. En todo caso, parecería que la singularidad de una vida, ubicados en un lugar y un tiempo determinados, se aleja cada vez más del mundo teórico de la ciencia, pero también de la totalidad de la cultura. Porque quizá el problema que se enfrenta en una crisis es la de dejarse representar por una fuerza, por un poder central, por 
una institución; ya que, ¿acaso la deficiencia mayor de una sociedad moderna no consiste precisamente en dejarse representar demasiado, por una teoría, por un gobierno, por un partido, por una política cultural manipulada desde los medios de comunicación y, finalmente, por el incesante bombardeo de lo actual? Representados, nombrados, saturados por la excesiva información a la que estamos expuestos; viviendo en una relación agonística entre el mundo y la conciencia que quiere dar sentido.

Nuestra experiencia del mundo es quizá muy reducida; no vemos ni sentimos a partir de la experiencia del pensamiento sino que percibimos a través de un lenguaje que llega filtrado y codificado por instituciones, organizaciones o sistemas que administran nuestro saber: el de lo inmediato. Por eso mismo, crisis que ha dejado un vacío que, paradójicamente, se ha saturado con noticias, información, intercambios, mensajes, mercancías, imágenes, etcétera, etcétera; y en ese aceleramiento, donde el tiempo y el espacio se trastocan, la historia, el sentido y la idea de progreso se perciben, desde la saturación y la falta, como una "atrofia de la experiencia", que también es un empobrecimiento de la percepción y la imaginación. Ahora que los medios de comunicación se empeñan en colmar todos los intersticios, lo que genera información ya no son los acontecimientos sino el "psicodrama visual" de una actualidad vacía, como diría Jean Baudrillard.

Bajtín entiende la vida como el devenir del acto ético, un acto responsable, lleno de riesgos y abierto a la experiencia. El pensamiento no puede divorciarse del cuerpo. Sin la creatividad, la emoción, la sensación, el deseo, no puede darse el pensamiento, ya que está anclado en la pasión de lo que sucede, le pasan cosas, le afectan. El pensamiento es un acto emocional y volitivo, posee una entonación y una voluntad, posee autoría, es decir, responsabilidad. De ahí que, para Bajtín, lo que une a esos dos mundos (el de la vida y el de la cultura) es la responsabilidad: núcleo del acto ético. Pero no entendamos 
responsabilidad como un término jurídico, ni como una obligación normativa derivada de algún código de conducta, sino como la capacidad de dar respuesta, como responsividad; esto es como el impulso por el que cada acto concreto vincula al ser humano con el mundo, con su entorno, con su experiencia. Para Bajtín: "da miedo todo lo que es técnico si se separa de la unidad única y si se abandona a la voluntad de la ley inmanente de su desarrollo; de vez en cuando puede irrumpir en esta unidad de la vida como una fuerza irresponsable, terrible, destructiva" (Bajtín, 1997: 229). Habría que preguntarse si no está separado también de esa "unidad única" la política, la cultura, la tecnología o la ciencia y, si no es para dar un poco de miedo, "la ley" que pueda irrumpir en cualquier momento en esa unidad, como poder o fuerza irresponsable, terrible y destructiva como temía Bajtín a principios del siglo pasado.

Todo lo que concierne a la experiencia posee una entonación de la singularidad de lo que somos. De ahí que el pensamiento verdaderamente abierto y creador significa, asimismo, la posibilidad de reaccionar, de recibir aquello que no soy "yo" en un abandono incesante a lo otro. La emoción y la voluntad tiñen a la realidad y al pensamiento de claroscuros; por ello no podemos hablar de verdades absolutas, ya que la experiencia del pensamiento nos remite no a lo que debe existir de una vez por todas y con validez universal sino a una renovación constante, a un cuestionamiento a partir de las preguntas y respuestas del momento, de afecciones y búsquedas. No se trata de insistir en la dualidad entre el acto pensante y la praxis, pues sin pensamiento, la praxis degenera en ejercicio carente de concepto. Pero tampoco marcha mucho mejor el pensamiento entendido como esfera particular, delimitada, ajena a una praxis posible, como pensaba Theodor Adorno. Me refiero así a un pensamiento participativo, aquel que no separa su acto de su producto, y que sólo puede concebirse en el ejercicio de la responsabilidad. 
La interacción entre el mundo de la cultura y el mundo de la vida se encuentra precisamente en el "entre", que vincula a modo de puente, y que apunta a la concepción de este puente como experiencia del lenguaje y del pensamiento; finalmente, cuando hablamos, cuando pensamos, estamos participando en una relación dialógica con lo otro, con el mundo. La pregunta sería si el pensamiento contemporáneo vincula la singularidad de la vida, la experiencia con su producto, con su resultado, con su obra creada, con su palabra. Del discurso del conocimiento, de la política o la ciencia habría que lograr un pasaje hacia la unidad de la experiencia, hacia la "unidad única", como la llama Bajtín.

Si hablamos del pensamiento como experiencia, tendríamos que detenernos para preguntarnos justamente sobre el valor de ésta. Una experiencia que, a decir de Walter Benjamin, se ha empobrecido. En el siglo pasado, en la década de los treintas, Benjamin, filósofo y crítico judeoalemán, escribió que "la cotización de la experiencia ha bajado", se refería a la generación que de 1914 a 1918, su generación, aquella que vivió la primera guerra mundial, había tenido una de las experiencias más terribles de la historia universal; después vendría la segunda guerra mundial, de la que Benjamin huyó de los nazis hasta que finalmente se suicidó en los Pirineos, en la frontera franco-española. En suma, un siglo caracterizado por la barbarie y el horror. En su ensayo "El narrador", Benjamin explica que la cotización de la experiencia ha bajado, que los que regresaban del campo de batalla regresaban mudos, no enriquecidos sino más pobres en experiencias comunicables. Supo ver en esa crisis de la experiencia el empobrecimiento, es decir, el desprendimiento de una porción tras otra de la herencia de la humanidad: "frecuentemente teniendo que darla en una casa de empeño por cien veces menos de lo que vale a cambio de que nos adelanten la pequeña moneda de lo actual". 
¿Y no estamos, justamente, saturados, bombardeados, mantenidos por esa moneda de lo actual?, ¿por la de lo inmediato?, ¿por lo que sólo nos llega a través de la información? Esto, la información, es precisamente lo que Benjamin contraponía a la narración (un género que consideraba como el arte de transmitir experiencias y que estaba tocando a su fin). Si decimos que el pensamiento es experiencia, y nuestra experiencia se ha empobrecido, entonces ¿nuestro pensamiento también se habrá empobrecido?:

Cada mañana, escribe Benjamin, nos instruyen sobre las novedades del orbe. A pesar de ello somos pobres en historias memorables. Esto se debe a que ya no nos alcanza acontecimiento alguno que no esté cargado de explicaciones. Con otras palabras: casi nada de lo que acontece beneficia a la narración, y casi todo a la información. Es que la mitad del arte de narrar radica precisamente, en referir una historia libre de explicaciones (1999: 113).

Frente a esa pobreza que usurpa cada vez más la vida, Benjamin vislumbra al mismo tiempo un enorme progreso de la técnica; así, en su ensayo "Experiencia y pobreza" aclara: "Sí, confesémoslo: la pobreza de nuestra experiencia no es sólo pobre de experiencias personales, sino de la generalidad de la humanidad. Se trata de una forma de nueva barbarie" (Benjamin, 1982: 135) y ¿a dónde, se pregunta, conduce al bárbaro esa pobreza de experiencias?; por una parte, sí a la destrucción, pero por otra, es ahí, en ese concepto de "barbarie", donde Benjamin recupera un lado digamos "positivo": ahonda en su sentido y aclara que esa barbarie lleva a la humanidad a comenzar desde el principio, como tabula rasa, a empezar de nuevo, a construir sin casi nada, sin mirar ni a izquierda ni a derecha. "Entre los grandes creadores siempre hubo aquellos implacables que lo primero que hicieron fue arrasar con todo. [...] porque fueron constructores" (Benjamin, 1982: 136). Una 
pobreza de la experiencia, así como un enorme desarrollo técnico y una sobresaturación informativa. Una barbarie que arrasa al mismo tiempo que construye, pero que no deja huellas, que lo ha devorado todo.

Cualquier crisis siempre conlleva síntomas que se manifiestan en la descomposición o destrucción de ciertos valores, pero al mismo tiempo en la transformación de los mismos o en la proyección de otros. Del mismo modo, el pensamiento no es algo a lo que hay que adecuarse, sino la tensión permanente entre las singulares y humanas condiciones de posibilidades que lo alimentan, y la historia o sus obras. Un pensamiento, entonces, que se proyecte sobre las relaciones teóricas y prácticas en las que se expresa cada momento de la historia y la cultura del presente. La acción del pensamiento consiste en la recreación de alternativas culturales o teóricas que interroguen a la subjetividad. No basta con mirar retrospectivamente a un pasado próximo o a un pensamiento más representativo para vislumbrar la realidad del presente; es preciso confrontar, detenernos en la fase del camino, porque el pensamiento supone una extraposición: no una pérdida del propio lugar, sino una comprensión y valoración desde otro lugar. Pensar es responder, encontrar consecuencias, introducirnos en la experiencia.

En efecto, el mundo existe no como una colección de datos que nuestros sentidos pueden captar y almacenar, haciendo de él una suma de objetos determinados, sino como un horizonte siempre latente de nuestra experiencia. El pensamiento, entonces, más que acumular o abarcar, busca, abre camino, deteniéndose en las grietas de este mundo inestable y olvidadizo, para provocar en cada instante un gesto inquisitivo e interrogativo. Se trataría, más bien, de una experiencia que remita a contenidos que están más allá del dato, quizá ausentes del campo limitado de la percepción, pero, paradójicamente, esos contenidos ausentes confieren significación al dato, a los objetos. ¿Por qué no imaginar que ese sumergirse en las pro- 
fundidades de las aguas de las que hablaba Melville, es un sumergirse en la realidad para captar ahí las posibilidades de la experiencia? Habría que reconocer que cuando experimentamos algo estimulamos no sólo nuestro propio ser sino la exterioridad sobre la cual actuamos. El ejercicio de la responsabilidad del pensamiento sería una forma de tender puentes por encima del abismo que separa al discurso del conocimiento y la política, del acto ético y la acción, franqueando así un pasaje hacia la unidad de la experiencia. ¿Será acaso, como pensaba Nietzsche, que lo que nos queda es la construcción de sentidos, y que eso es un asunto humano, demasiado humano, o tal vez la única acción posible en el momento actual? Como escribe Adorno sobre Nietzsche: "en el fondo, su consigna 'vivir peligrosamente' [...] se expresaría mejor así: 'pensar peligrosamente', espolear el pensamiento, no retroceder por nada ante la experiencia de la cosa, no dejarse atar por ningún consenso de lo previamente pensado" (Adorno, 1993: 14).

No se trata, entonces, de sanar una crisis, de "restablecer el orden", como últimamente escuchamos tanto, sino de sumergirnos en la realidad, de ser buceadores del pensamiento, de descender y regresar a la superficie con los ojos inyectados en sangre; es decir, marcados, tatuados, afectados por la experiencia del pensamiento. Una experiencia que nos lleve nuevamente no a tierra firme sino a la incertidumbre de sabernos siempre en alta mar.

\section{BIBLIOGRAFÍA}

Adorno, Theodor, Consignas, trad. Ramón Bilbao, Buenos Aires, Amorrortu, 1993.

Bajtín, Mijaíl, Hacia una filosofía del acto ético. De los borradores y otros escritos, trad. Tatiana Bubnova, Barcelona, Anthropos/ Universidad de Puerto Rico, 1997. 
Benjamin, Walter, "El narrador", en Para una crítica de la violencia y otros ensayos, Iluminaciones IV, trad. Roberto Blatt, Madrid, Taurus, 1999, pp. 111-134.

- "Experiencia y pobreza", en Para una crítica de la violencia y otros ensayos, México, Premiá, 1982, pp. 133-142 (La nave de los locos).

Gilles, Deleuze, Conversaciones 1972-1990, trad. José Luis Pardo, Valencia, Pre-textos, 1996. 